\title{
Environmental and Economic Impact of Forest Fires in Puerto Rico 2013-2014
}

\author{
Méndez-Tejeda Rafael1, Santos-Corrada María², Ortiz-Morales Sergio², \\ Claudio-Vargas Oscar ${ }^{2}$ \\ ${ }^{1}$ Natural Science Department, Atmospherical Science Laboratory, University of Puerto Rico-Carolina Campus, \\ Carolina, Puerto Rico \\ ${ }^{2}$ School of Business and Entrepreneurship, University of Turabo, Gurabo, Puerto Rico \\ Email: rafael.mendez@upr.edu, msantoscorrada@suagm.edu
}

Received 5 January 2015; accepted 30 March 2015; published 31 March 2015

Copyright (C) 2015 by authors and Scientific Research Publishing Inc.

This work is licensed under the Creative Commons Attribution International License (CC BY).

http://creativecommons.org/licenses/by/4.0/

c) (i) Open Access

\section{Abstract}

This study presents an analysis of the impact of forest fires in Puerto Rico for the period from 2013-2014. The climatological factors analyzed included precipitation, temperature, relative humidity, and wind. Several factors have combined to the increase of these forest fires, among others, a decrease in precipitation during this period, as well as an increase in the human involvement in these fires from approximately 40\% occurs in the night period (5:00 pm to 8:00 am), where the weather conditions do not favor the appearance of these phenomena. An increase in fires of $44 \%$ occurred in 2013 compared to 2014, causing an economic loss of $\$ 13.8$ million. Fire also adversely affected the flora and fauna of the island, but this was not evaluated in this paper.

\section{Keywords}

Fires Forest, Wildfire; Economic Impact of Forest fires, Precipitation and Weather Conditions

\section{Introduction}

Fire affects virtually all terrestrial ecosystems, but it occurs more commonly in some than in others. Many studies that have examined the relationship between fire and weather variables were primarily devoted to the wildfires and/or forest fires in large wilderness areas, such as the U.S. West region, the Northwest Territories of Canada, and the large landmass of Australia. Byram (1954), analyzed the enormous effect of weather on forest fires, while the effect of sunshine on fire-season severity was analyzed by Turner (1970).

Ellis et al. (2010), suggest that, just prior to the start of the Industrial Revolution, only 5\% of the ice-free land surface had been substantially modified by humans for agriculture and settlement, but by AD 2000, this had in- 
creased to 55\%. This global landscape transformation was associated with widespread clearing and burning of forests to create farmland and with the combustion of large quantities of fossil fuels. Puerto Rico lacks studies on the impact of forest fires. Located in the center of the Caribbean (between latitudes $180^{\circ} 31^{\prime}$ and $170^{\circ} 55^{\prime} \mathrm{N}$ and longitudes $65^{\circ} 37^{\prime}$ and $67^{\circ} 17^{\prime} \mathrm{N}$, between the Atlantic Ocean and the Caribbean Sea), and including five smaller nearby islands, Puerto Rico measures $180 \mathrm{~km}$ long and $65 \mathrm{~km}$ wide, making a total area of $8897 \mathrm{~km}^{2}$ MéndezTejeda \& Peñalbert (2001); Rossi (2010). Precipitation is primarily affected by troughs imbedded in easterly waves during summer months and cold fronts during winter months (Figure 1). The lowest amount of precipitation in Puerto Rico occurs from December to March. The rainy season is characterized by two peaks, usually occurring during May and September (Ramirez et al., 2007).

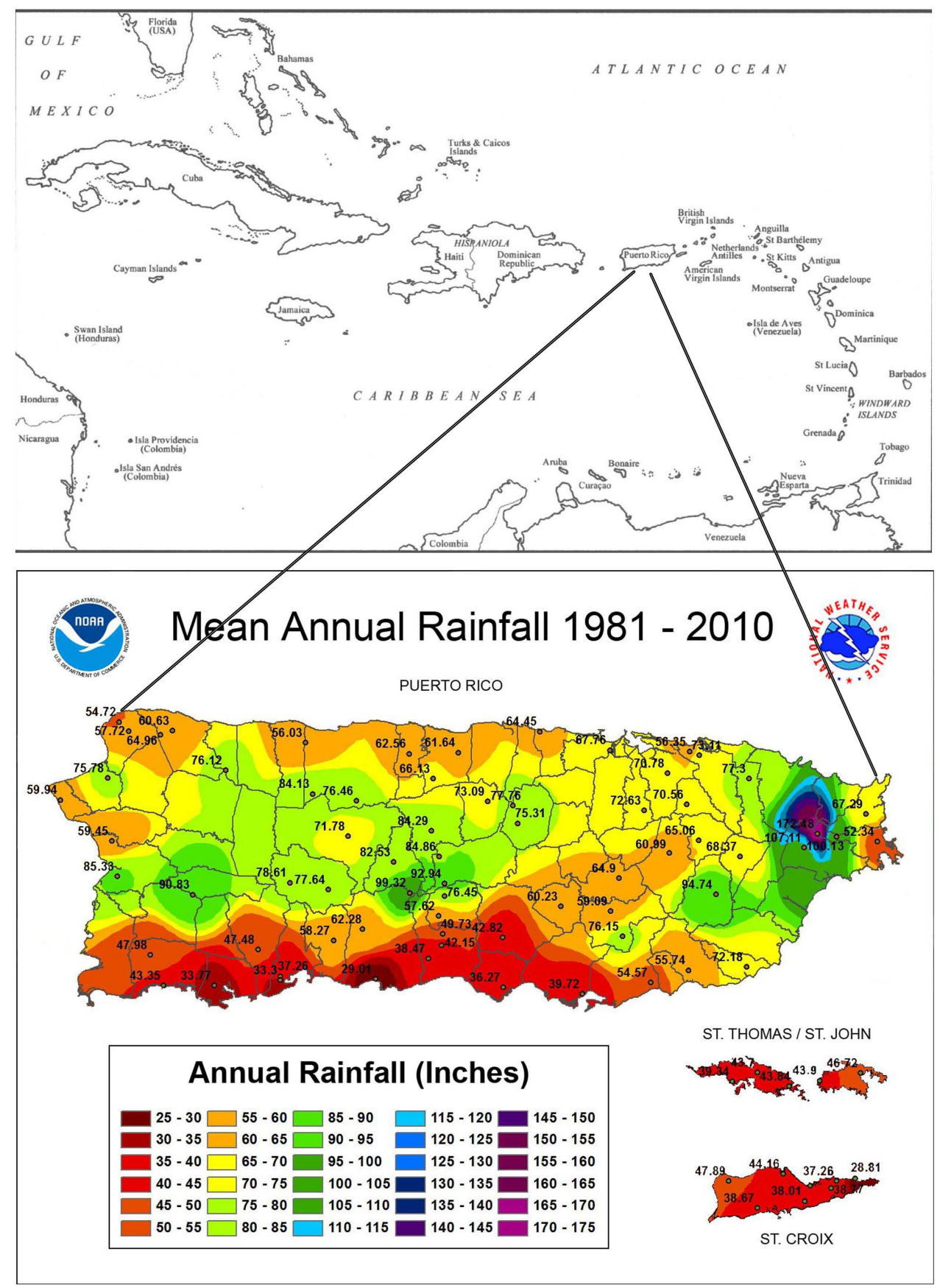

Figure 1. The Caribbean region and precipitation trends in Puerto Rico for the period 1981-2010. 
A few researchers have attempted to simulate and predict the rainfall process in Puerto Rico. For example, Comarazamy (2001), successfully used the regional atmospheric modeling system (RAMS) to simulate monthly rainfall over Puerto Rico during April 1998, which was an unusually wet month. However, RAMS failed to simulate the rainy season (i.e., August and September) because of difficulties in correcting for initial soil moisture conditions.

The increase in the number of forest fires in Puerto Rico during 2013 and 2014 has caused serious environmental and economic losses, resulting in the destruction of the flora and fauna of the island. Changes in precipitation patterns on the island of Puerto Rico should therefore be considered when examining the causes of the increasing number of forest fires. According to Moritz (2012), climate change will become a fact for most people only when its effects hit close to home. For this reason, creating awareness of the measures necessary to adapt to climate change is important, as this will precede wider commitment to mitigating climate change itself.

Global analyses of past and current fire activity have provided insights into the interaction between climate and anthropogenic burning. Analyses of charcoal in sediment records over the past 21,000 years suggest that fire regimes respond primarily to changes in regional climate and/or climate-induced vegetation changes, Power et al. (2008).

Dominguez-Martínez and Rodríguez Trejo (2008), report that each year, on average, some 21,000 registered fires affect approximately 677,000 ha (32.2 ha/per fire) in Central America (population 161,448,000 inhabitants). The worst year in the history of the region was 1998, with 56,731 fires registered over 2,330,000 ha (41 ha/per fire), which represented the equivalent of 3 percent of the forest surface and a surface area 2.25 times greater than the average annual deforestation rate for the zone. The rate of deforestation varies according to the country, although in general it is high. The average for the region is about a 1037,000 ha/per annum or 1.3 percent per annum (FAO, 1998).

A forest fire is a fire of natural or anthropogenic origin, and can cause harm to people, property, and/or the environment Cochrane (2009). This type of fire spreads without control across rural lands composed mainly of dry herbs and grasses. It can also be defined as an unwarranted and uncontrolled fire that is fueled by materials of plant origin. This type of fire can destroy everything in its wake, thus damaging the flora and fauna of a given region Cochrane (2003). Forest fires are growing in size and frequency across the tropics. They continuously erode fragmented forest edges, becoming unintended ecological disturbances that transcend deforestation to degrade vast regions of standing forest, thereby diminishing ecosystem services and the economic potential of these natural resources Lafon \& Quiring (2012).

\section{Methodology}

The behavior of the weather conditions is important in determining the occurrence of forest fires, according to Byram (1954) and Cochrane (2009). For this reason, we analyzed the behavior of these meteorological parameters for the island of Puerto Rico during the period of 2013-2014.The Fire Department of Puerto Rico (FDPR) is divided into six Fire Zones (FZs) and each of the FZs consists of two districts (see Figure 2). The geographical

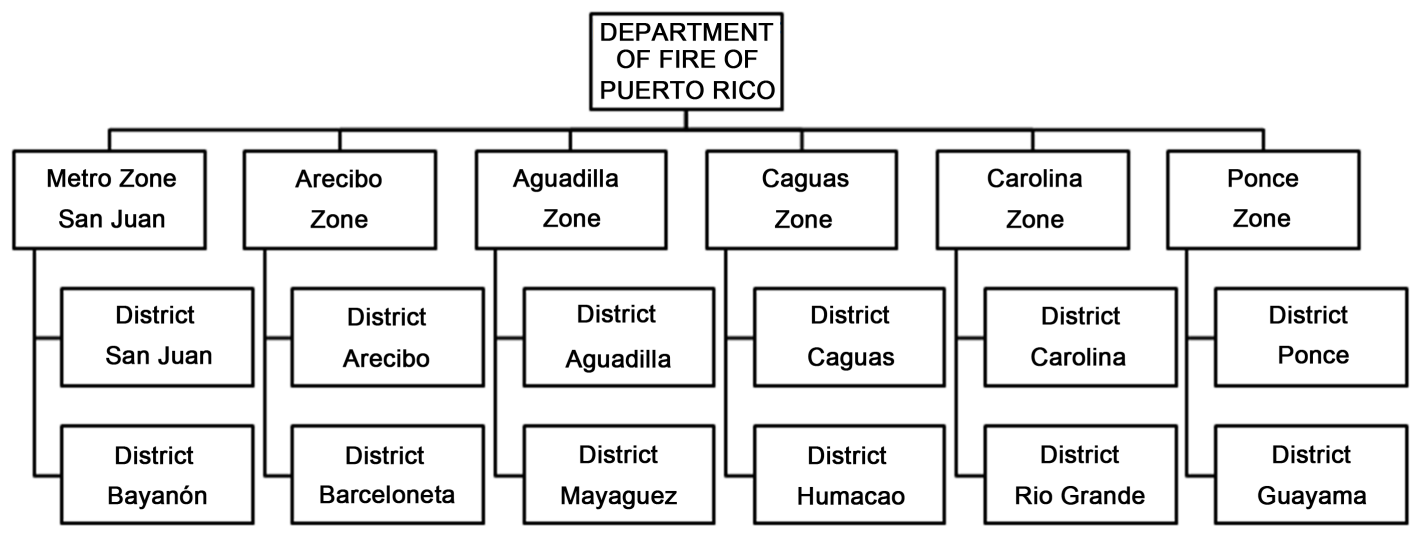

Figure 2. The six zones of the Fire Department of Puerto Rico (FDPR) and the 12 fire districts. (Source: Fire Department of Puerto Rico) an region and precipitation trends in Puerto Rico for the period 1981-2010. 
dimensions of the island are small (approximately $8897 \mathrm{~km}^{2}$ ), so we selected a weather station for each of the firefighter zones and analyzed the precipitation and temperature during the analysis period. In terms of the relative humidity factor, which is of utmost importance for the generation of forest fires, a data series exists for the climate of the island; however, we obtained data from two stations of the Western Regional Climate Center, at Guánica and Camp Santiago. Both stations belong to the Department of Ponce FZ (South Puerto Rico), the region most impacted by fires. The available data were insufficient to analyze relative humidity for the whole island, but the island's value for this parameter normally exceeds $40 \%$.

In terms of the number of forest fires, we hypothesized that the conditions during the day were much more conducive to the generation of forest fires. For this reason, fires are divided into two periods: those that occurred between 8:00 am and 5:00 pm and those that occurred between 5:00 pm and 8:00 am, with the objective of analyzing the nature of the contribution of the climatic factors to the increase in the number of forest fires It has been taken into consideration that in the period (from 5:00 pm to 8:00 am), called night the weather conditions are unfavourable the spread of forest fires and similarly for the spontaneous combustion.

\subsection{Precipitation}

The regions most affected by forest fires are the southern and western regions of the island, which include Guayama, Ponce, and Mayagüez, where rainfall decreased over the period from 2013-2014 (Figure 3). During 2013, precipitation decreased throughout the island, mostly affecting the southern region of the Island, which is the location of the Camp Santiago Station that serves the Ponce FZ. As shown in Figure 3, the decrease was more intense in the months of January, February, and March in both years, reaching its peak in 2013. In the Figure 4 can be seen a sharp decline in precipitation in the year 2013 and 2014, coming to have a deficit of rain fall in a $20 \%$, which contributed to a rise in the number of forest fires.

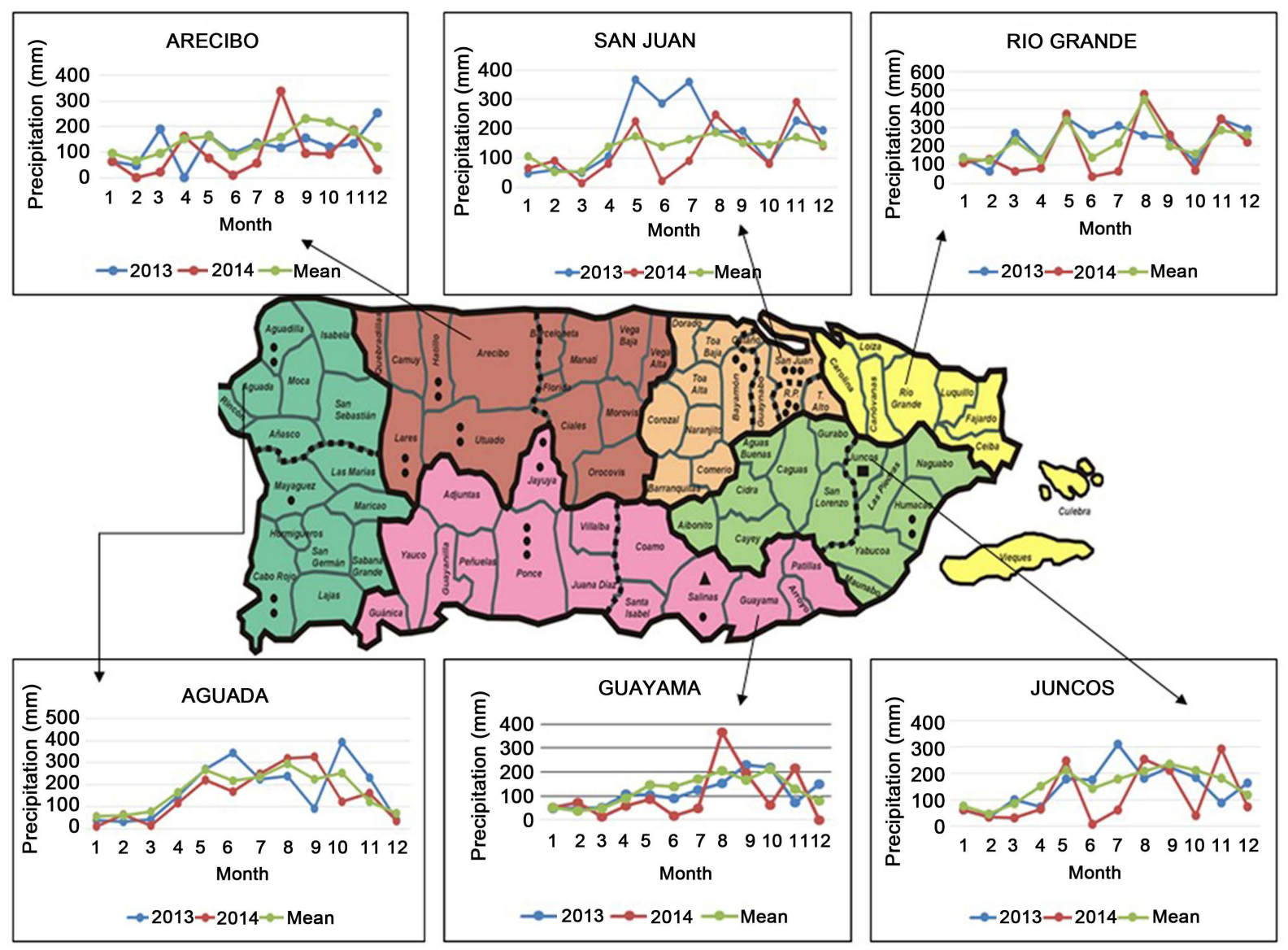

Figure 3. Rainfall for the six fire zones for the period of 2013-2014. 


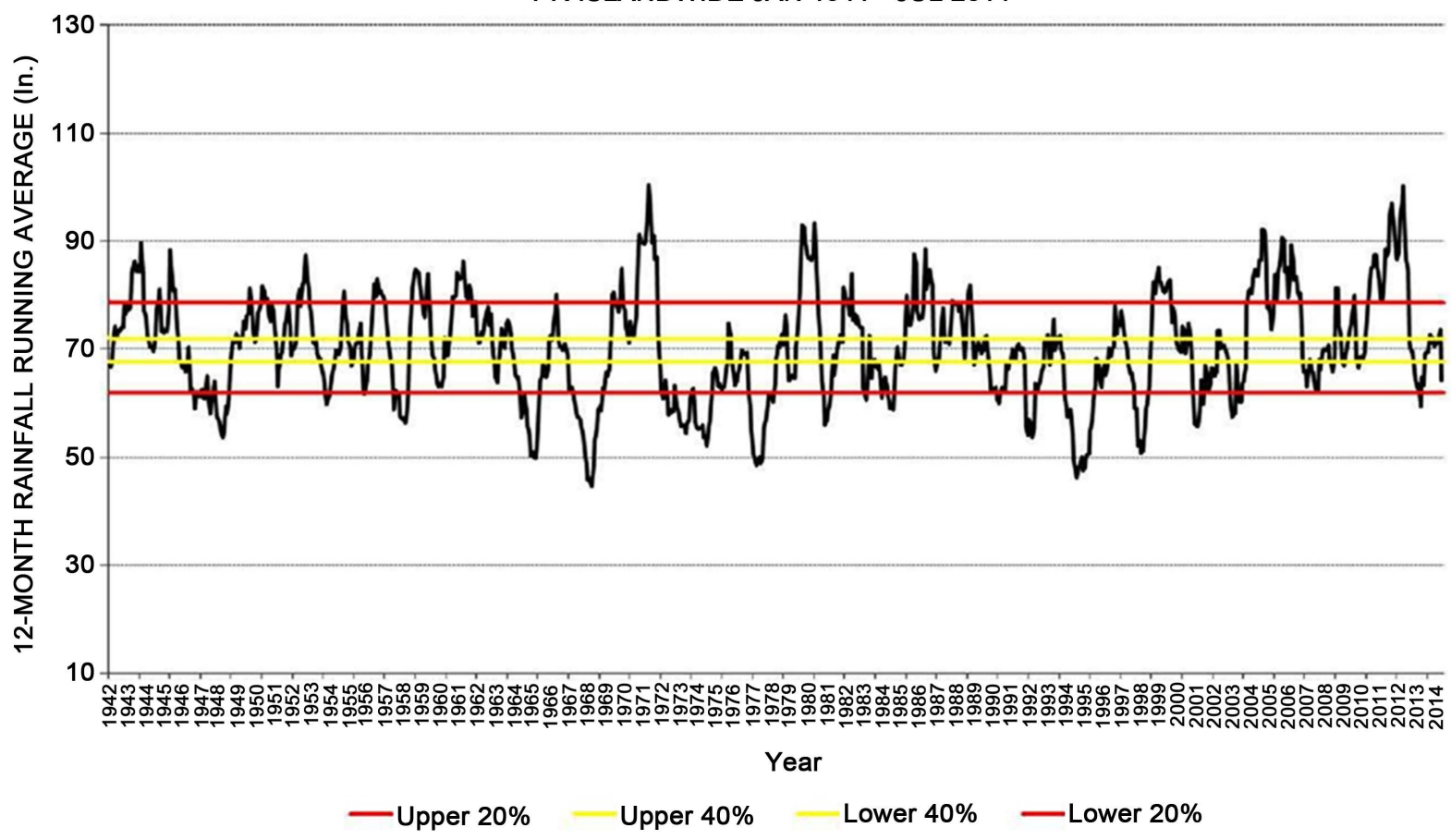

Figure 4. The trend in precipitation in Puerto Rico (PR) from 1941-2014. Shows a sharp decline in precipitation in 2013 and 2014, resulting in a deficit in rainfall of $20 \%$, which contributed to a rise in the number of forest fires. (Source: Ernesto Morales and Odalys Martinez, National Weather Service).

\subsection{Temperature}

The majority of forest fires for the years 2013 and 2014 occur in the districts of Fire Department composed of Ponce, Guayama (south of the island), and the district of formed by Mayagüez and Aguadilla (West). The maximum temperatures were highest in the district of San Juan, where close to the maximum values for this area occurred in 2013; however, the numbers of fires did not show the same trend. The District of Río Grande had the same temperature tendency in both 2013 and 2014 (Figure 5(a) and Figure 5(b) and Figure 6(a) and Figure 6(b) respectively). During the period analyzed, the values closest to the extreme values of maximum temperature occurred in the north of the island, the region that has a high rainfall.

\subsection{Relative Humidity}

Relative humidity is a factor of great importance in the generation of forest fires, particularly in regards to spontaneous combustion. A relative humidity drop below $30 \%$ creates conditions that are more favorable for wildfires because the air can absorb more moisture from the fuel. When the fuel contains less moisture, less time is required to heat it to the combustion point. Light fuels such as grass, dry leaves, crystals, and lightning, in combination with low humidity, high temperature, and a favorable wind, create ideal conditions for wildfires.

To analyze the Figure 7 and Figure 8 for the stations of Camp Santiago (ZF on Ponce) and Lajas (ZF of Mayagüez), you may notice that the values of relative humidity were generally about $40 \%$ with rare exceptions are below this value.

\subsection{Wind}

We analyzed the wind speed and direction as important factors in the generation and propagation of forest fires. In Puerto Rico, the prevailing winds are the Trade Winds (NE to SE) and the breezes from sea and land. During the period studied, for the stations at Camp Santiago and Guánica (FZ from Ponce, Figure 9), the following behavior was recorded: At Camp Santiago, the wind remained within the window above the Trade Winds. Overall, 


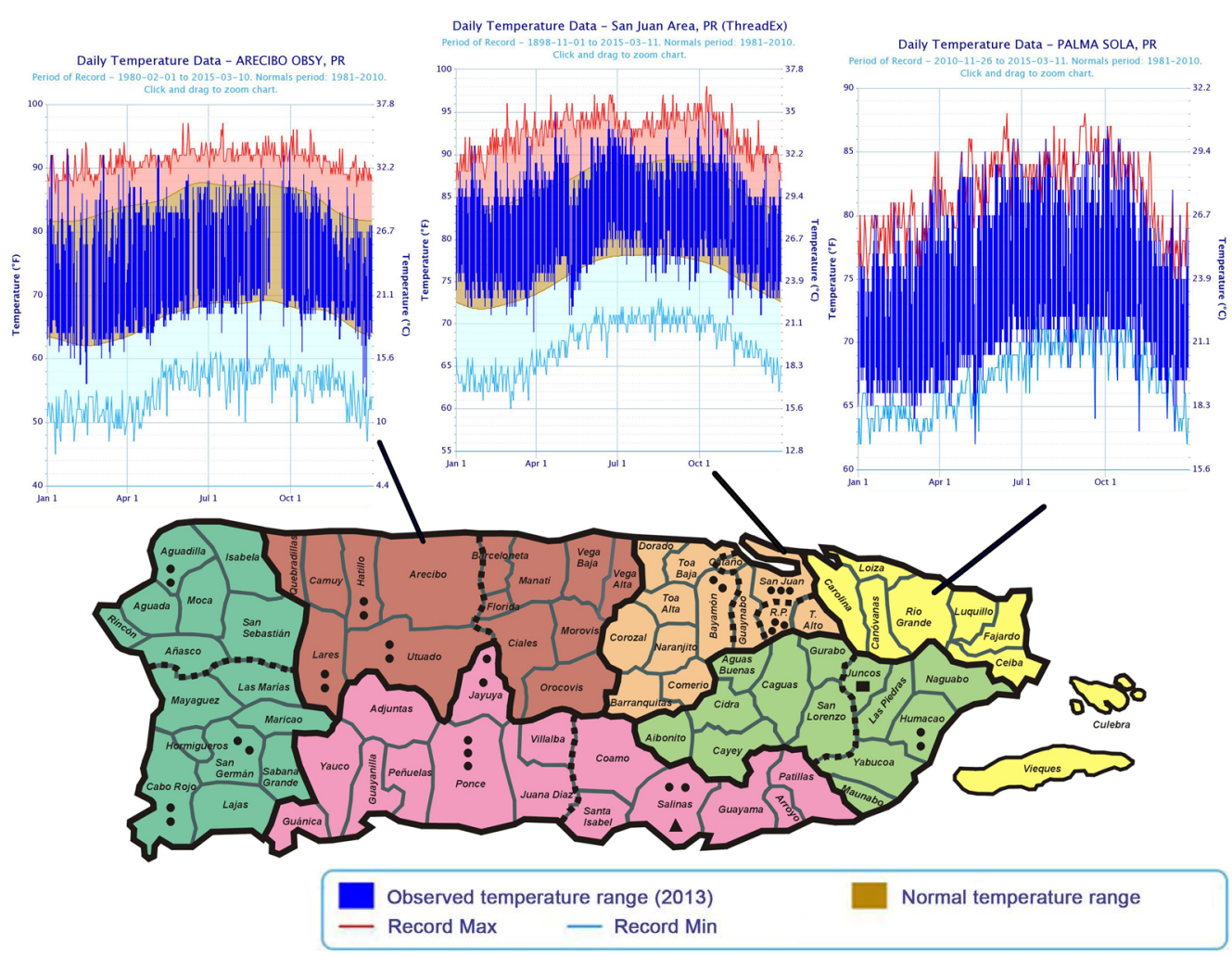

(a)

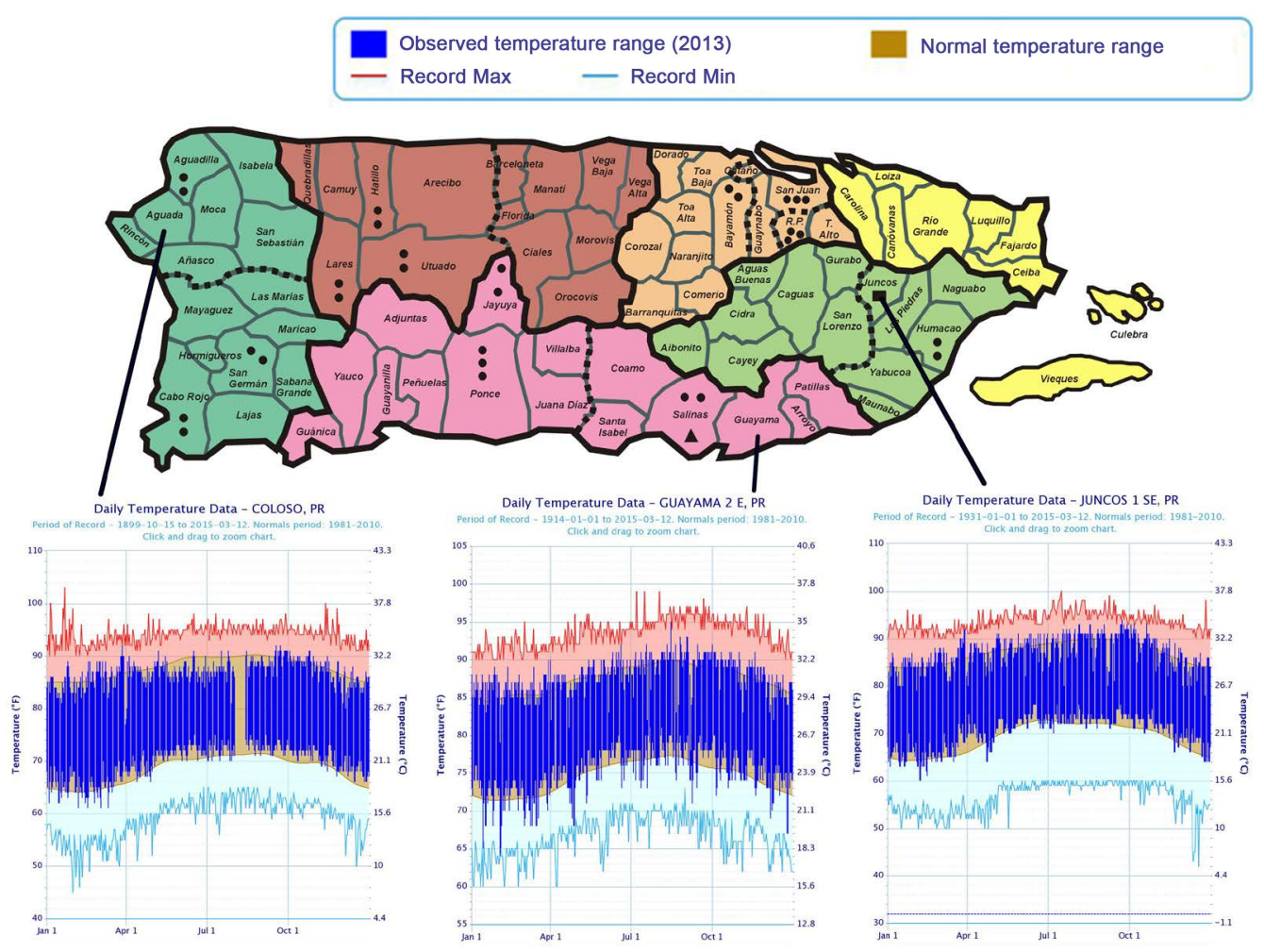

(b)

Figure 5. (a) Temperature trends in the six Fire Zones (FZs) for 2013. (Source: National Weather Service); (b) Temperature trends in the six Fire Zones (FZs) for 2013. (Source: National Weather Service). 


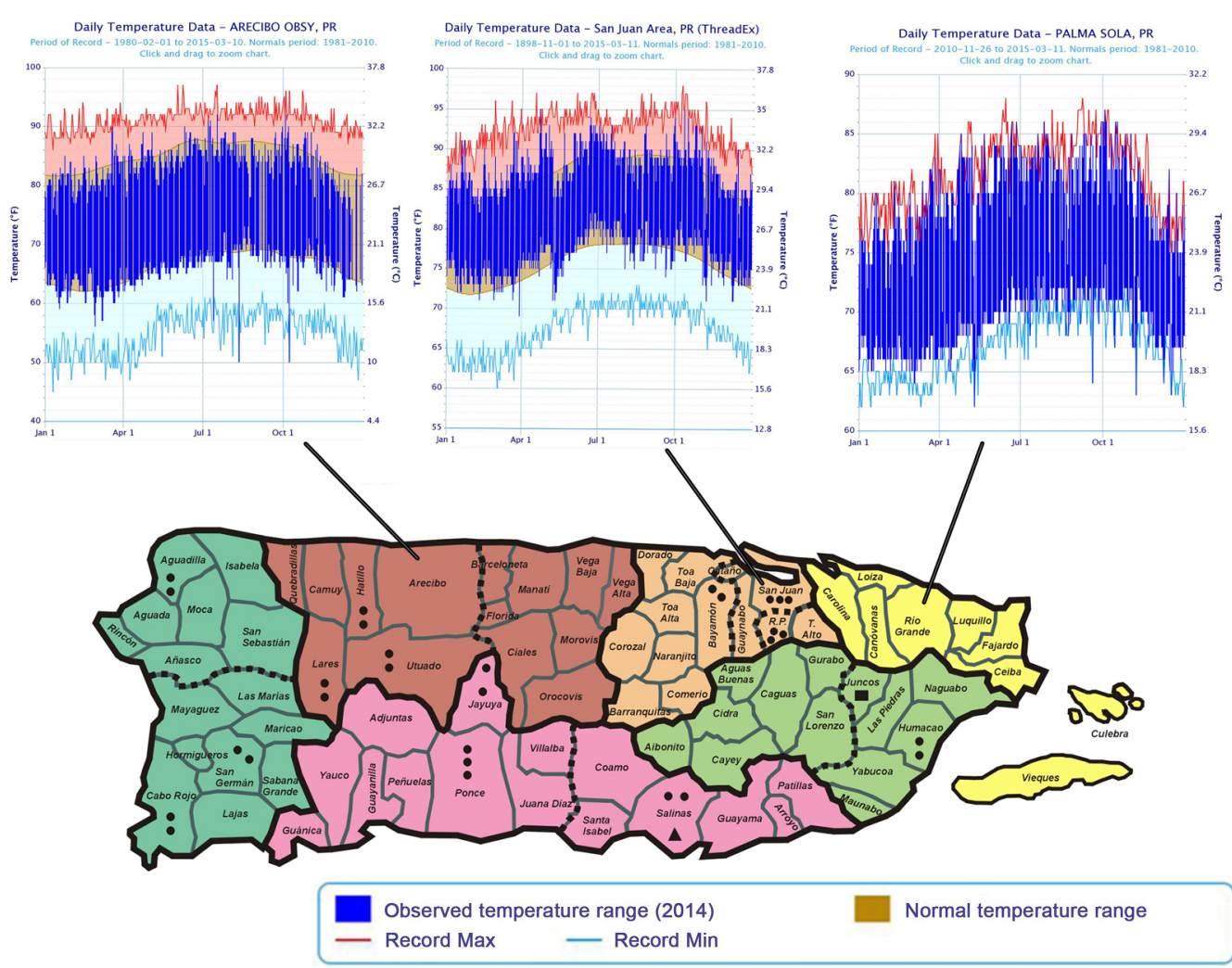

(a)

Observed temperature range (2014)
- Record Max $\quad$ Record Min
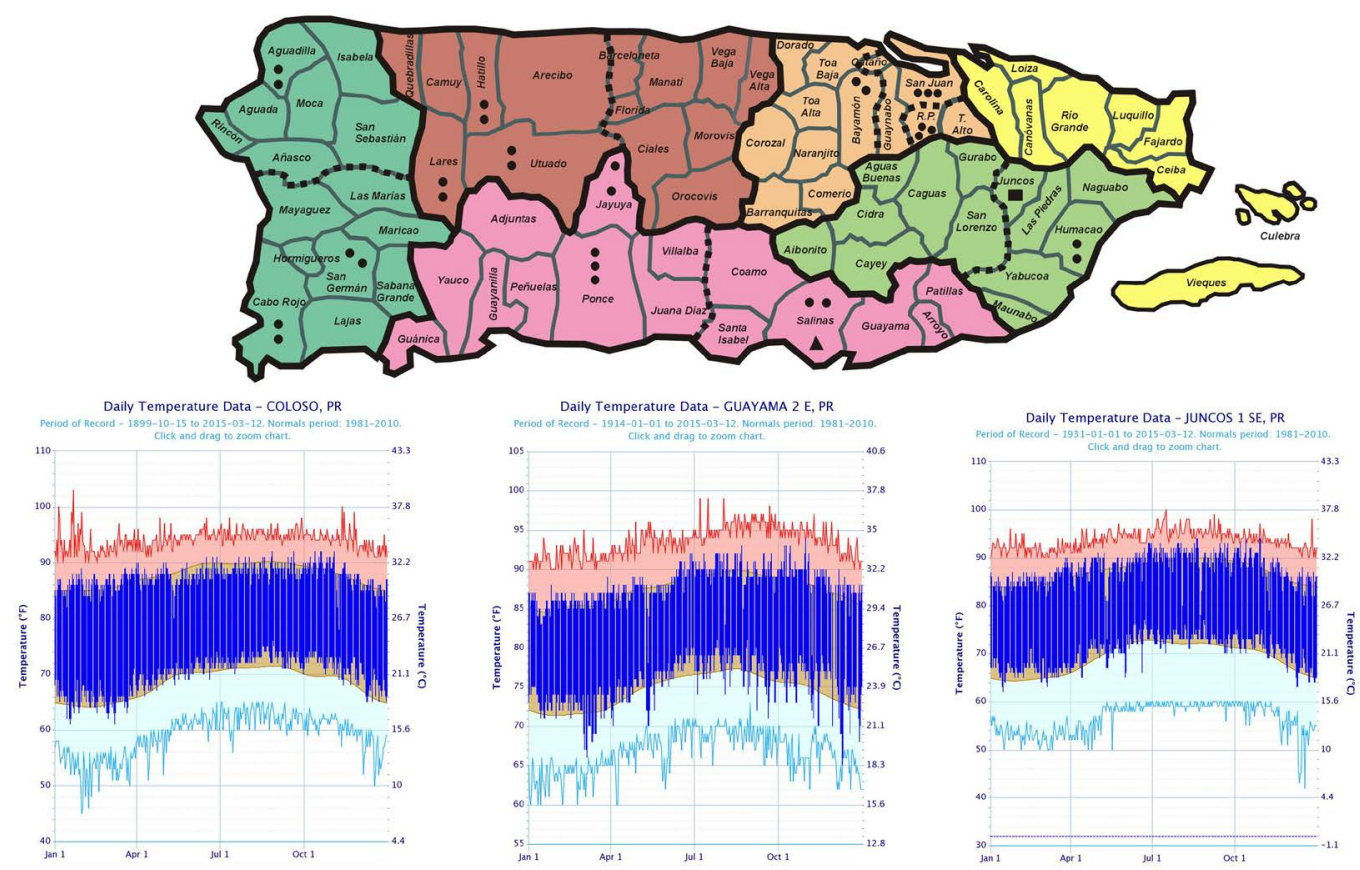

(b)

Figure 6. (a) Temperature trends in the six Fire Zones (FZs) for 2014. (Source: National Weather Service); (b) Temperature trends in the six Fire Zones (FZs) for 2014. (Source: National Weather Service). 


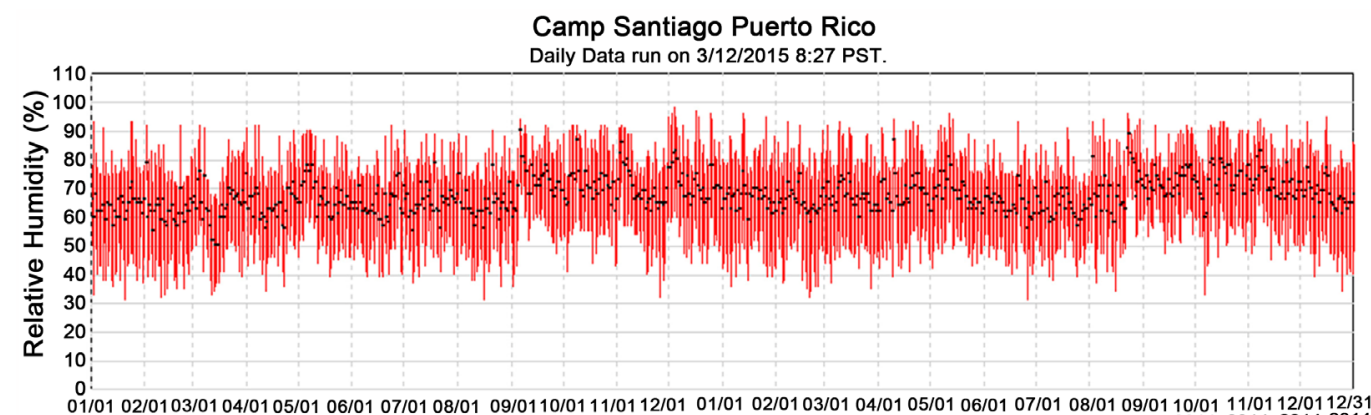

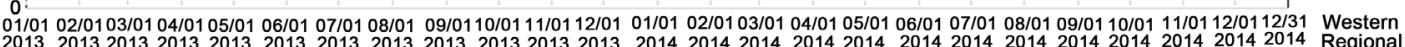
Day of Year

Daily Humidity (Average and Range)

Figure 7. Relative humidity measurements for the Camp Santiago Station (Ponce Fire Zone) for the years 2013-2014. (Source: Western Regional Climate Center).

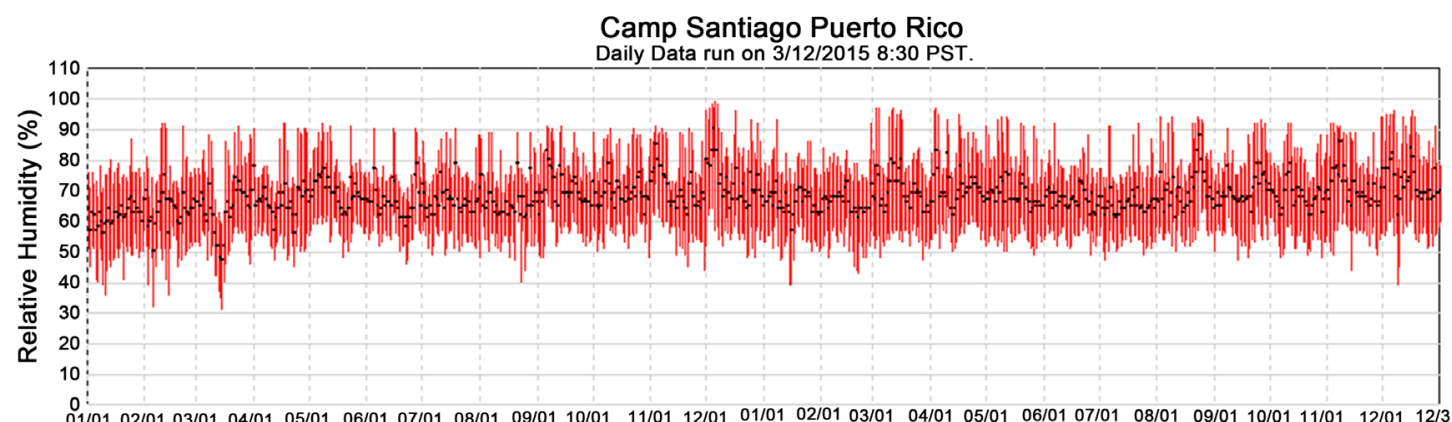

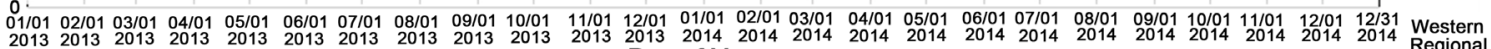
Day of Year
Daily Humidity (Average and Range)

Figure 8. Relative humidity measurements for the Guánica Station (Ponce Fire Zone) for the years 2013-2014 (Source: Western Regional Climate Center).

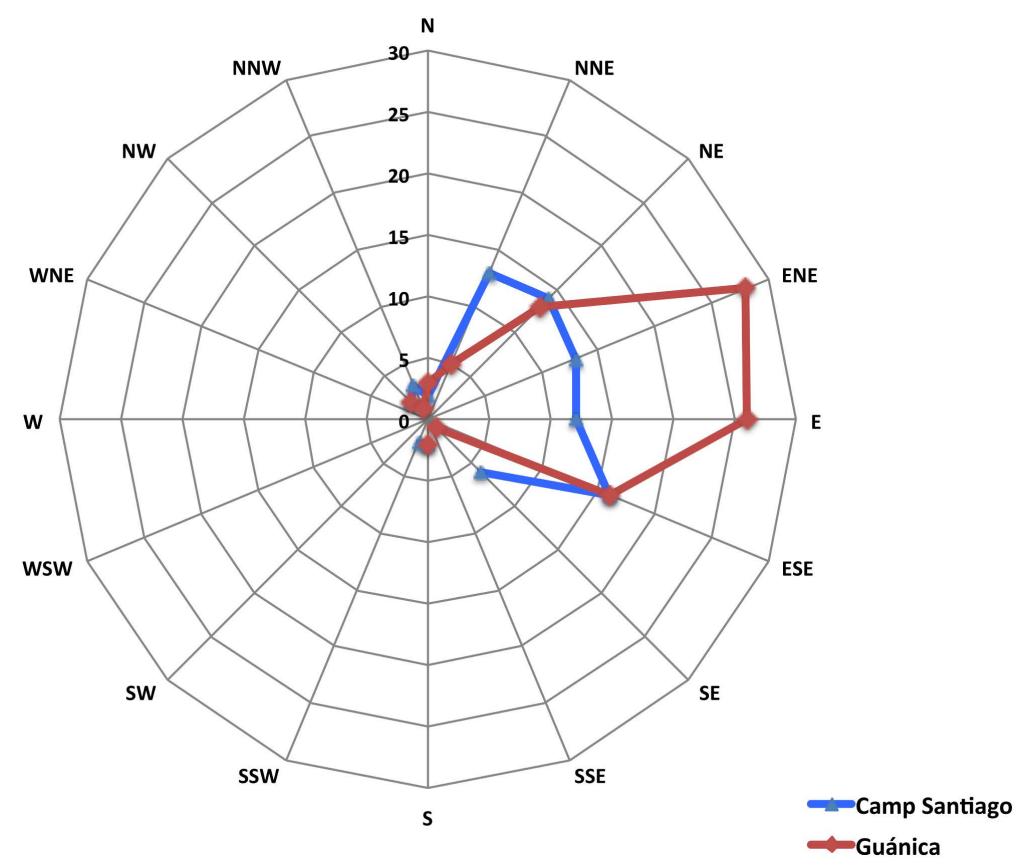

Figure 9. Peak wind velocities for the Camp Santiago and Guánica stations for the period 2013-2014. The direction of the prevailing trade winds (Alisios wind) was from NE to SE. (Source: Western Regional Climate Center). 
$15 \%$ of the winds are from the SE, with a speed range between 19 to $25 \mathrm{mph}$, while $12 \%$ are from the $\mathrm{E}$ and show similar behavior. With respect to the Station of Guánica, the behavior is similar, except that the winds are of lesser intensity.

\section{Results}

Much forest fire activity occurred throughout the island in 2013. The fire districts most affected were Mayagüez and Aguadilla, which are located in the same FZ. The Mayagüez district experienced 1054 forest fires in Aguadilla and 944 forest fires, for a total of 1998 forest fires during 2013. In second place was the Ponce FZ, composed of the districts of Ponce and Guayama, where 836 and 485 forest fires occurred, respectively, for a total of 1321 forest fires.

In 2014, the number of fires decreased dramatically. The Ponce FZ was again the most active area, with a total of 1167 forest fires: 773 occurred in Ponce and 394 in Guayama. This represented a decrease of approximately12\%. By contrast, the decrease in fires in the Mayagüez FZ, which experienced 881 fires, was more than $44 \%$ when compared to 2013. The months with the greatest number of fires were January to March 2013, where 3760 forest fires were reported, in comparison with 2014, where only 1597 forest fires were reported, for a reduction of 2173 (42\%). However, a 27\% rise in the number of fires was recorded in June 2014, when 310 fires occurred, compared to June 2013, when only 84 forest fires were reported. This increase could be a result of drought that occurred throughout the island in 2013 and 2014.

\section{Analysis}

The hypothesis that forest fires should occur in the daytime period was confirmed in the case of Puerto Rico. The period of increased occurrence of fire was from 8:00 am to 5:00 pm, accounting for $62 \%$ of the fires in 2013 (Figure 10) and 2014 (Figure 11); however, when the climatic conditions were less favorable, this decreased to $38 \%$. In the fire areas in Arecibo and Barceloneta, night time fires accounted for $43 \%$ and a similar behavior appeared in Guayamazone, which experienced $42 \%$ night time fires. The economic, environmental, and social damage in 2013 generated by 4567 forest fires (Figure 12), over an area of approximately 68,000 $\mathrm{m}^{2}$ (6800 ha), was an estimated \$13.8 million (Source FRPR). In 2014, 2302 forest fires occurred (Figure 13), covering a surface area of approximately $64,000 \mathrm{~m}^{2}$ (6400 ha) and causing an economic impact of $\$ 8.6$ million. This value is calculated without considering the impact on the flora and fauna of the region. The two economic sectors most affected were agriculture and livestock. Most of the burned areas corresponded to grasses of high nutritional value for cattle feeding, so the decrease in pasture forced farmers to buy food for their cattle.

The economic impact of these forest fires does not include the machinery and equipment used to control the fires, nor the amount and cost of man-hours in this work. The Fire Department of Puerto Rico does not maintain these types of statistics, making the full impact difficult to quantify.

\section{Conclusion}

This study considered the effects of climatic factors such as temperature, rainfall, relative humidity, and wind on the occurrence of forest fires. A similar analysis was carried out in Taiwan by Yen and Chen (2004). Despite some possible human errors/bias in manually prepared fire reports, two significant temporal signals of fire-occurrence frequency were identified: annual and diurnal. Relationships possibly exist between these two fire occurrence signals and some meteorological variables.

Forest fires of natural origin are most commonly caused by lightning and electrical storms, particularly when they are unaccompanied by rain. However, they can also be as a result of anthropogenic causes; i.e., fires due to human activities in the mountains and forests, arising either from failure to take necessary precautions or from accidents. Misuse of the forests has caused thousands of hectares to be razed in forest fires. Human action, without a doubt, causes the majority of forest fires in Puerto Rico. These fires are generated by carelessness or negligence in handling heat sources in the presence of combustible vegetation. The majority of forest fires on the island of Puerto Rico occur primarily in three months of the year as a result of various types of human interventions, some of which are even criminal.

Approximately $40 \%$ of the forest fires have occurred in the night period, where atmospheric conditions are unfavorable for spontaneous combustion. This finding helps to confirm the participation of human (anthropo- 
Monthly Fires by Districts 2013

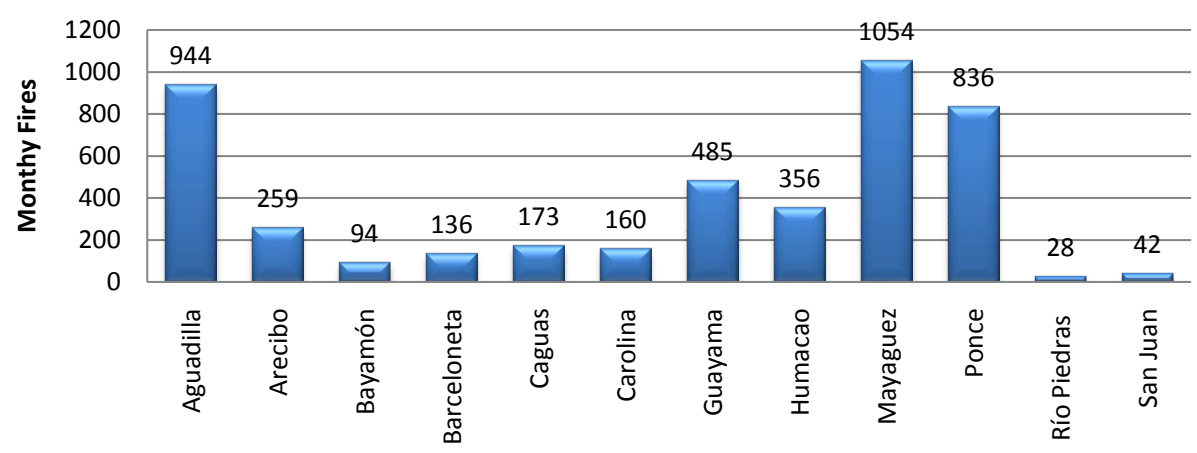

Figure 10. Shows the monthly number of travel wildfires occurred on the island in 2013. Source: (FDPR).

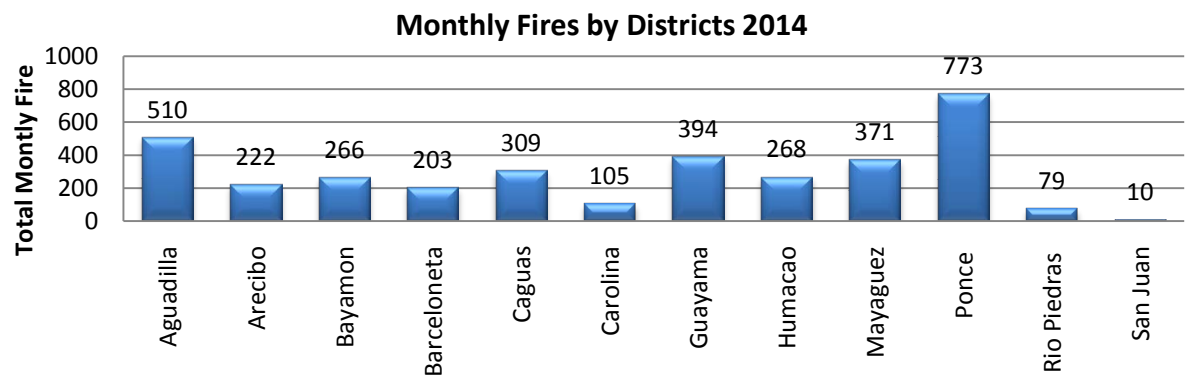

Districts

Figure 11. Shows the monthly number of travel wildfires occurred on the island in 2014 . Source: (FDPR).

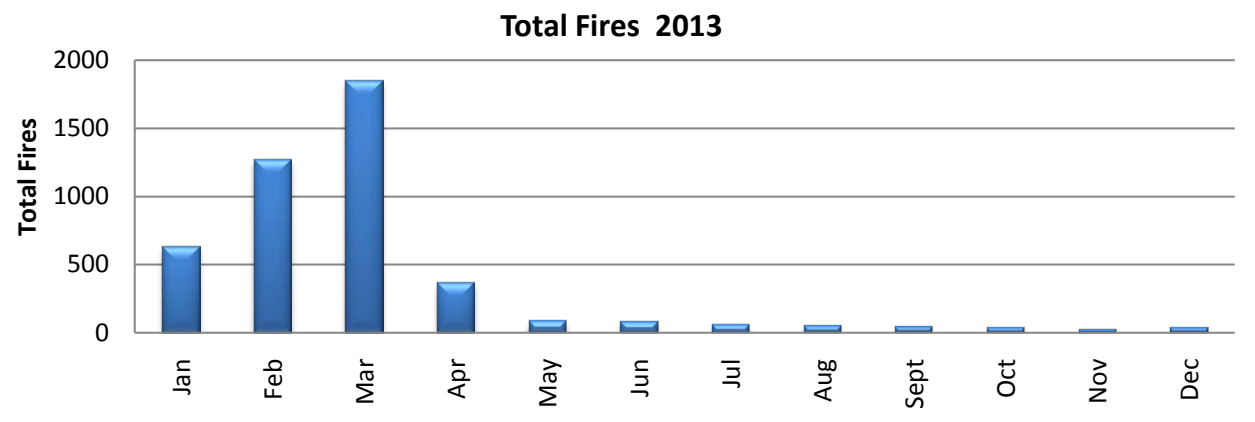

Figure 12. Shows the Total Fires of wildfires occurred on the island in 2013. Source: (FDPR).

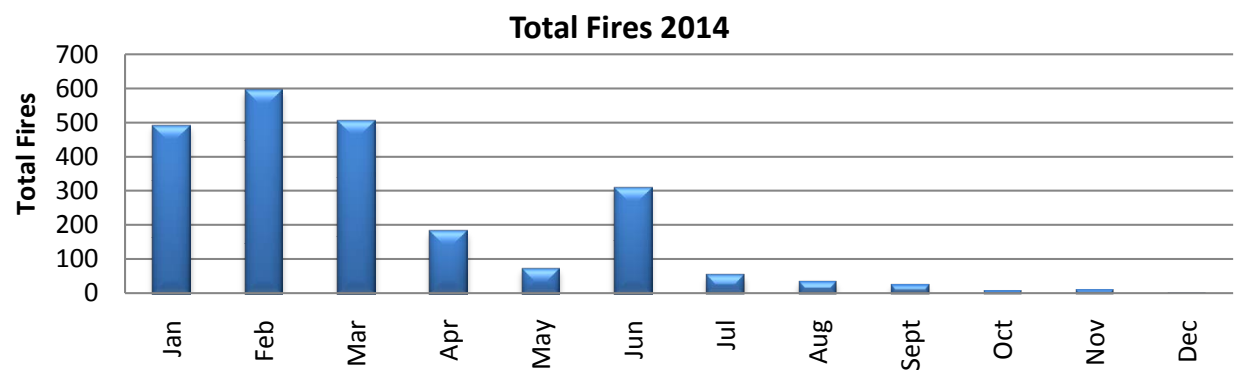

Figure 13. Shows the Total Fires of wildfires occurred on the island in 2013. Source: (FDPR).

genic) actions in these forest fires, which are initiated by recklessness or negligence in the operation of a heat source under ideal weather conditions. 
We conclude that the majority of forest fires on Puerto Rico are produced directly by human action; that is to say, by criminals. Our final recommendation is that the Fire Department and the Department of Environmental and Natural Resource (DNRA) should strengthen citizen education, which had extraordinary results in the reduction of the fires in 2014 compared with 2013. This is essential if Puerto Rico is to coexist sustainably with the rest of our planet.

\section{Acknowledgements}

The authors wish to thank the Fire Department of Puerto Rico and to the National Weather Service to provide the data for this study, in particular to Odalys Martínez.

\section{References}

Byram, G. M. (1954). Atmospheric Conditions Related to Blow-Up Fires. USDA Forest Service, Southeastern Forest and Range Experiment Station Paper No. 35, 34.

Cochrane, M. A. (2003). Fire Science for Rainforests. Nature, 421, 913-919. http://dx.doi.org/10.1038/nature01437

Cochrane, M. A. (2009). Tropical Fire Ecology: Climate Change, Land Use, and Ecosystem Dynamics. Heidelberg: Springer/Praxis Publishing, 645. http://dx.doi.org/10.1007/978-3-540-77381-8

Comarazamy, D. E. (2001). Atmospheric Modeling of the Caribbean Region: Precipitation and Wind Analysis in Puerto Rico for April 1998. M.S. Thesis, Department of Mechanical Engineering, University of Puerto Rico, Mayagüez, Puerto Rico, 112.

Dominguez-Martinez, R., \& Rodriguez-Trejo, D. A. (2008). Forest Fires in Mexico and Central América. Proceedings of the Second International Symposium on Fire Economics, Planning, and Policy: A Global View. http://www.fs.fed.us/psw/publications/documents/psw_gtr208en/psw_gtr208en_709-720_dominquez.pdf

Ellis, E.C., Klein Goldewijk, K., Siebert, S., Lightman, D., \& Ramankutty N. (2010). Anthropogenic Transformation of the Biomes, 1700 to 2000. Global Ecology and Biogeography, 19, 589-606.

FAO (1998). Los programas forestales nacionales y el desarrollo forestal sostenible en América Latina, by J. Gamboni \& C. Carneiro. Proyecto GCP/RLA/127/NET. Santiago, Chile, FAO Regional Office for Latin Americaand the Caribbean.

Lafon, W. C., \& Quiring, S. M. (2012). Relationships of Fire and Precipitation Regimes in Temperate Forests of the Eastern United States. Earth Interactions, 16, 1-15. http://dx.doi.org/10.1175/2012EI000442.1

Méndez-Tejeda, R., \& Peñalbert, J. (2001). Acid Rain in Carolina, Puerto Rico. Environmental Health Science. http://www.tandfonline.com/doi/pdf/10.1080/10473289.2002.10470815

Moritz, M. A. (2012). Wildfires Ignite Debate on Global Warming. Nature, 487, 273. http://dx.doi.org/10.1038/487273a

Power, M. J., Marlon, J., Ortiz, N. et al. (2008). Changes in Fire Regimes Since the Last Glacial Maximum: An Assessment Based on a Global Synthesis and Analysis of Charcoal Data. Climate Dynamics, 30, 887-907. http://dx.doi.org/10.1007/s00382-007-0334-x

Ramirez-Beltran, N., Lau, W. K. M., Winter, A., Castro, J. M., \& Escalante, N. R. (2007). Empiricalprobability Models to Predict Precipitation Levels over Puerto Rico Stations. Monthly Weather Review, 135, 877-890.

Rossi, S. A. (2010). Impact of Siting Changes on Temperature Observations at Cyril E. King Airport, Saint Thomas,U.S. Virgin Islands and Luis Munoz Marin International Airport, San Juan, PR. (Report No. NWS SR-232). Fort Worth, TX: United States Department of Commerce, Science and Technology Services Division. http://www.srh.noaa.gov/images/sju/climo/sr232.pdf

Turner, J. A. (1970). Hours of Sunshine and Fire Season Severity over the Vancouver Forest District. The Forestry Chronicle, 46, 106-111. http://dx.doi.org/10.5558/tfc46106-2

Yen, M. C., \& Chen, T. C. (2004). Fire Nature of a Subtropical Maritime Island in East Asia: Taiwan. Journal of Applied Meteorology, 43, 537-547. http://dx.doi.org/10.1175/1520-0450(2004)043<0537:FNOASM>2.0.CO;2 